\title{
IMPLEMENTASI MODEL-MODEL INFORMATION GAP DALAM PEMBELAJARAN KAIWA BERBASIS DARING
}

\author{
Yeni $^{1}$, I.W. Sadyana ${ }^{2}$, G.S. Hermawan ${ }^{3}$ \\ Prodi Pendidikan Bahasa Jepang \\ Universitas Pendidikan Ganesha \\ Singaraja, Indonesia \\ e-mail: yenirahmansifa@gmail.com, wayan.sadyana@undiksha.ac.id, satya.hermawan@undiksha.ac.id
}

\begin{abstract}
Abstrak
Tujuan dalam penelitian ini adalah untuk mengetahui kemampuan berbahasa Jepang mahasiswa setelah diimplementasikan model-model information gap dalam pembelajaran kaiwa berbasis daring dan untuk mengetahui respon mahasiswa terhadap implementasi model-model information gap dalam pembelajaran kaiwa berbasis daring. Penelitian ini menggunakan metode eksperimen kuasi (Quasi Experimental) dengan pendekatan kuantitatif. Desain penelitian yang digunakan adalah one grup pretest posttest design. Instrumen yang digunakan berupa tes berbicara dan angket/kuesioner dalam bentuk Google Form. Berdasarkan hasil posttest diketahui 86\% mahasiswa yang diimplementasikan model-model information gap dalam pembelajaran kaiwa berbasis daring memperoleh nilai di atas 80 sedangkan sisanya $14 \%$ mahasiswa memperoleh nilai di bawah 80. Gain hasil pretest dan posttest menunjukkan peningkatan rata-rata nilai sebesar 2.04 . Dengan demikian, kemampuan berbahasa Jepang mahasiswa setelah diimplementasikan modelmodel information gap dalam pembelajaran kaiwa berbasis daring mengalami peningkatan dan implementasi model-model information gap efektif dalam pembelajaran kaiwa berbasis daring. Selanjutnya berdasarkan hasil angket/kuesioner diperoleh respon positif dari sebagian besar responden terhadap implementasi model-model information gap dalam pembelajaran kaiwa berbasis daring.
\end{abstract}

Kata kunci: Information Gap, Pembelajaran Kaiwa, Kemampuan Berbahasa Jepang

\section{Abstract}

The purposes of this study are to investigate Japanese ability of university student after being taught by using information gap in learning Kaiwa and to investigate the responses of university student who are taught by using information gap in learning Kaiwa. This study uses Quasi Experimental method which belongs to Quantitative approach. To be specified, this study use one group pretest posttest design. The instruments used are speaking test and questionnaires. The findings point out $86 \%$ students reach the score above 80 in posttest and $14 \%$ students reach the score under 80 in posttest. The gain of pretest and posttest result is 2.04. The result above indicate that there is difference of Japanese ability university student who are taught by using information gap in learning Kaiwa. To sum up, the use of information gap is effective in teaching Kaiwa. Furthermore, based on the result of questionnaire, most of student give positive responses toward the use of types information gap in learning Kaiwa.

Keywords : Information Gap, Learning Kaiwa, Japanese Ability

\section{Pendahuluan}

Saat mempelajari bahasa Jepang pembelajar harus menguasai empat keterampilan berbahasa secara terintegrasi sehingga dapat menggunakan bahasa Jepang baik secara lisan maupun tulisan. Keterampilan berbahasa tersebut meliputi keterampilan menyimak, keterampilan berbicara, keterampilan membaca, dan keterampilan menulis. Sutedi (2009:39) mengemukakan bahwa pembelajar bahasa Jepang dituntut untuk menguasai empat keterampilan berbahasa dengan baik agar pembelajar mampu berkomunikasi dengan menggunakan bahasa Jepang secara lisan maupun tulisan.

Keterampilan berbicara merupakan keterampilan yang sangat penting dan utama untuk dikuasai oleh pembelajar bahasa Jepang di antara empat keterampilan berbahasa yang lain. Hal ini dikarenakan keterampilan berbicara berkaitan dengan aspek penggunaan bahasa untuk berkomunikasi secara lisan. Berbicara adalah alat atau sarana untuk 
mengungkapkan ide atau gagasan kepada lawan bicara sehingga maksud dari pembicara dapat tersampaikan kepada lawan bicara. Tarigan (2008:16) menjelaskan bahwa berbicara adalah suatu alat untuk mengkomunikasikan gagasan-gagasan yang disusun serta dikembangkan sesuai dengan kebutuhan-kebutuhan sang pendengar atau penyimak. Ketika mempelajari bahasa Jepang, seseorang tidak hanya akan belajar menyimak, membaca dan menulis, tetapi juga belajar berbicara. Kemampuan berbicara bahasa Jepang tidak hanya dilihat dari kemampuan seseorang dalam memahami bahasanya saja tetapi juga dilihat dari kemampuan berkomunikasi menggunakan bahasa tersebut.

Di Program Studi Pendidikan Bahasa Jepang, Universitas Pendidikan Ganesha keterampilan berbicara bahasa Jepang diajarkan pada mata kuliah kaiwa. Capaian pembelajaran mata kuliah kaiwa, yaitu mampu mengaplikasikan kemampuan bahasa Jepang dengan menunjukkan penguasaan yang baik pada aspek berbicara bahasa Jepang dan terampil berkomunikasi secara lisan dengan menggunakan ungkapan sesuai dengan situasi tutur. Berdasarkan hal tersebut, untuk mengajarkan kaiwa diperlukan metode pembelajaran kaiwa yang berpusat pada siswa (student centered learning) dan berbasis pendekatan komunikatif, yaitu information gap.

Information gap means literally "the gap in information" among people, that is, somebody has information about something that another doesn't have (Kazuhiro, 2012). Dari pengertian tersebut dapat dikatakan bahwa information gap mengatasi kesenjangan informasi di antara seseorang yang memiliki informasi tentang sesuatu yang tidak dimiliki orang lain. Selanjutnya Kazuhiro (2012) menyebutkan ada bermacam-macam tipe information gap yang dapat digunakan untuk kegiatan berbahasa di kelas, antara lain: (a) Information gap antara dua siswa, (b) Information gap antara dua atau lebih grup, (c) Information gap antara satu siswa (atau guru) dan seluruh siswa yang lain, dan (d) Information gap seluruh siswa.

Information gap dilaksanakan dengan kegiatan berpasangan menggunakan dua lembar kerja (worksheet) yang berbeda yang mana siswa melengkapi informasi yang hilang dengan bertanya dan menjawab pertanyaan. Dengan demikian, akan tercipta pertukaran informasi antara satu siswa dengan siswa lain sehingga kegiatan berbahasa akan lebih bermakna, mendekati komunikasi aktual, dan juga efektif.

Berdasarkan latar belakang di atas, peneliti bermaksud melakukan eksperimen dengan mengimplementasikan model-model information gap dalam pembelajaran kaiwa berbasis daring dengan tujuan untuk mengetahui kemampuan berbahasa Jepang mahasiswa setelah diimplementasikan model-model information gap dalam pembelajaran kaiwa berbasis daring dan untuk mengetahui respon mahasiswa terhadap implementasi model-model information gap dalam pembelajaran kaiwa berbasis daring.

\section{Metode}

Penelitian ini menggunakan metode eksperimen kuasi (Quasi Experimental) dengan pendekatan kuantitatif. Desain penelitian yang digunakan one grup pretest posttest design. Populasi dalam penelitian ini adalah mahasiswa Program Studi Pendidikan Bahasa Jepang Universitas Pendidikan Ganesha dan sampel yang digunakan adalah mahasiswa tingkat I yang sedang menempuh mata kuliah Kaiwa Shokyu. Penentuan sampel penelitian menggunakan purposif sampling karena materi kaiwa yang diajarkan menggunakan modelmodel information gap merupakan materi tingkat dasar (shokyu). Teknik pengumpulan data menggunakan instrumen penelitian berupa tes lisan (berbicara) dan angket/kuesioner dalam bentuk Google Form. Teknik analisis data tes dilakukan dengan menggunakan statistik deskriptif.

\section{Hasil dan Pembahasan}

Berdasarkan analisis data dalam penelitian ini, dapat diinterpretasikan secara keseluruhan dalam pembahasan berikut ini. Penelitian ini dilaksanakan selama tiga kali pertemuan dengan alokasi waktu 2 x 50 menit dengan menggunakan zoom cloud meeting. Pada awal pertemuan dilaksanakan pretest untuk mengetahui kemampuan awal mahasiswa. 
Dari hasil pretest rata-rata nilai mahasiswa sebesar 79.96. Setelah diterapkan 3 kali perlakuan (treatment), pada pertemuan terakhir dilaksanakan posttest untuk melihat kemampuan akhir mahasiswa. Dari hasil posttest menunjukkan rata-rata nilai mahasiswa sebesar 82. Rata-rata nilai ini mengalami peningkatan sebesar 2.04 dari rata-rata nilai pretest. Berdasarkan hasil posttest diketahui bahwa 86\% mahasiswa memperoleh nilai di atas 80 sedangkan $14 \%$ sisanya memperoleh nilai di bawah 80 . Dengan demikian, dapat disimpulkan bahwa kemampuan berbahasa Jepang mahasiswa setelah diimplementasikan model-model information gap dalam pembelajaran kaiwa berbasis daring adalah baik. Peningkatan nilai posttest mahasiswa tersebut tidak lain disebabkan oleh adanya perlakuan (treatment) yang diberikan, yaitu implementasi model-model information gap dalam pembelajaran kaiwa berbasis daring.

Berdasarkan perhitungan angket/kuesioner diperoleh $P=79.33$. Menurut tabel kriteria diketahui bahwa presentasi 79.33 termasuk dalam kriteria kuat. Hal ini menunjukkan bahwa implementasi model-model information gap dalam pembelajaran kaiwa berbasis daring efektif untuk meningkatkan kemampuan berbahasa Jepang mahasiswa. Berkaitan dengan implementasi model-model information gap dalam pembelajaran kaiwa berbasis daring diperoleh respon positif dari responden, yaitu selama proses pembelajaran kaiwa berbasis daring melalui implementasi model-model information gap, diketahui bahwa lebih dari setengah responden berpendapat bahwa implementasi model-model infromation gap dapat membantu mahasiswa menerima dan menyerap materi dengan baik, mampu menciptakan komunikasi yang efektif antara dosen dan mahasiswa, mampu menciptakan komunikasi yang efektif antar mahasiswa, mampu menciptakan dan mengarahkan sikap positif pada mahasiswa saat proses pembelajaran, mampu menghubungkan materi dengan pengetahuan yang dimiliki mahasiswa, mampu memberikan kesempatan kepada mahasiswa untuk terlibat aktif selama proses pembelajaran, mampu memberikan umpan balik yang positif terhadap hasil belajar, dan mampu meningkatkan kemampuan berbahasa Jepang mahasiswa.

Implementasi model-model information gap dalam pembelajaran kaiwa berbasis daring dalam penelitian ini yang pertama adalah information gap antara dua siswa. Pada pelaksanaan information gap ini siswa membentuk pasangan kemudian siswa pertama diberi lembar kerja (worksheet) B1 dan siswa kedua diberi lembar kerja (worksheet) B2 dengan tema 木村くんの一日 (Kimura kun no ichi nichi). Siswa bertukar informasi dan mengisi bagian yang kosong di lembar kerja masing-masing.
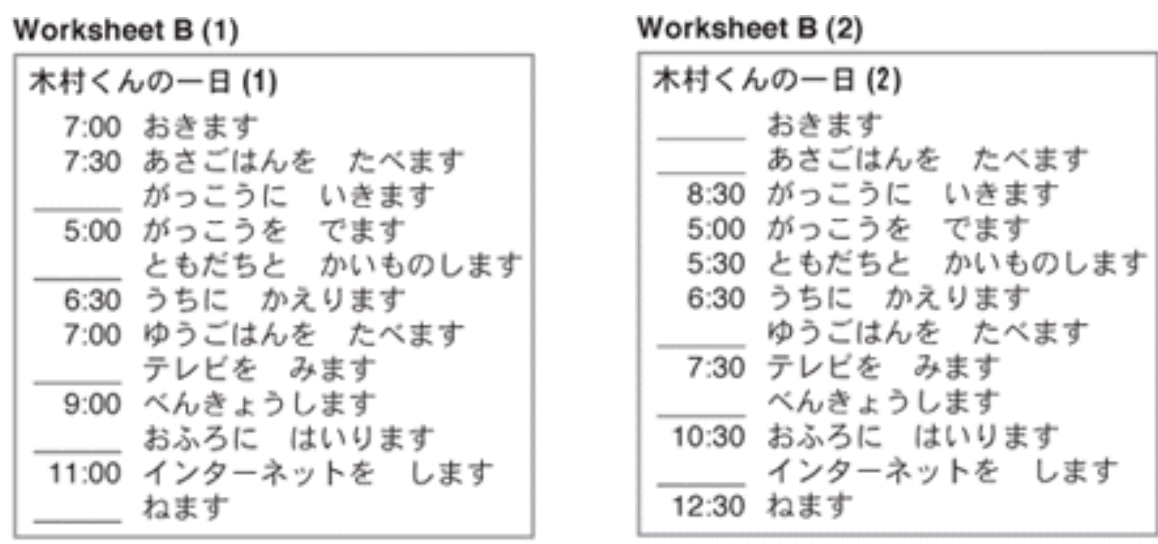

Gambar 1. Worksheet B

Information gap antara dua siswa dapat juga divariasikan dengan kegiatan seperti berikut ini. Setiap siswa diberikan kartu dari lembar kerja (worksheet) C kemudian siswa melengkapi jadwal Kimura kun dengan mengajukan pertanyaan satu sama lain. Contoh pertanyaan yang diajukan seperti berikut ini.

Siswa 1: 木村くんは 何時に 何をしますか。

Siswa 2: あさ 8 時半に 学校に 行きます。木村くんは 何時に 何をしますか。 
Siswa 1:よる11時に インターネットを します。 Worksheet C

\begin{tabular}{|c|c|c|}
\hline $\begin{array}{l}\text { あさ 7:00 } \\
\text { おきます }\end{array}$ & $\begin{array}{c}\text { Фうがた } 5: 30 \\
\text { ともだちと かいものします }\end{array}$ & $\begin{array}{c}\text { よる9:00 } \\
\text { べんきょうします }\end{array}$ \\
\hline \begin{tabular}{l}
\multicolumn{2}{c}{ あさ 7:30 } \\
あさごはんを たべます
\end{tabular} & $\begin{array}{c}\text { ゆうがた } 6: 30 \\
\text { うちに かえります }\end{array}$ & $\begin{array}{c}\text { よる } 10: 30 \\
\text { おふろに }\end{array}$ \\
\hline 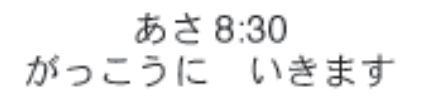 & \begin{tabular}{l}
\multicolumn{2}{c}{ よる7:00 } \\
ゆうこはんん たべます
\end{tabular} & $\begin{array}{c}\text { よる11:00 } \\
\text { インターネットを します }\end{array}$ \\
\hline $\begin{array}{l}\text { ゆうがた 5:00 } \\
\text { がっこうを でます }\end{array}$ & $\begin{array}{l}\text { よる 7:30 } \\
\text { テレビを みます }\end{array}$ & $\begin{array}{l}\text { よる } 12: 30 \\
\text { ねます }\end{array}$ \\
\hline
\end{tabular}

\section{Gambar 2. Worksheet C}

Selanjutnya implementasi model-model information gap dalam pembelajaran kaiwa berbasis daring yang kedua adalah information gap antara dua kelompok atau lebih. Pada pelaksanaan information gap ini siswa membentuk empat kelompok, setiap kelompok diperlihatkan satu dari empat gambar pada lembar kerja (worksheet) $\mathrm{E}$, dan siswa membuat catatan tentang gambar tersebut. Setelah itu, siswa membentuk kelompok baru yang terdiri dari empat orang, satu dari masing-masing kelompok sebelumnya. Di kelompok baru siswa melaporkan keluarga yang mereka lihat di gambar dan anggota kelompok membuat catatan.

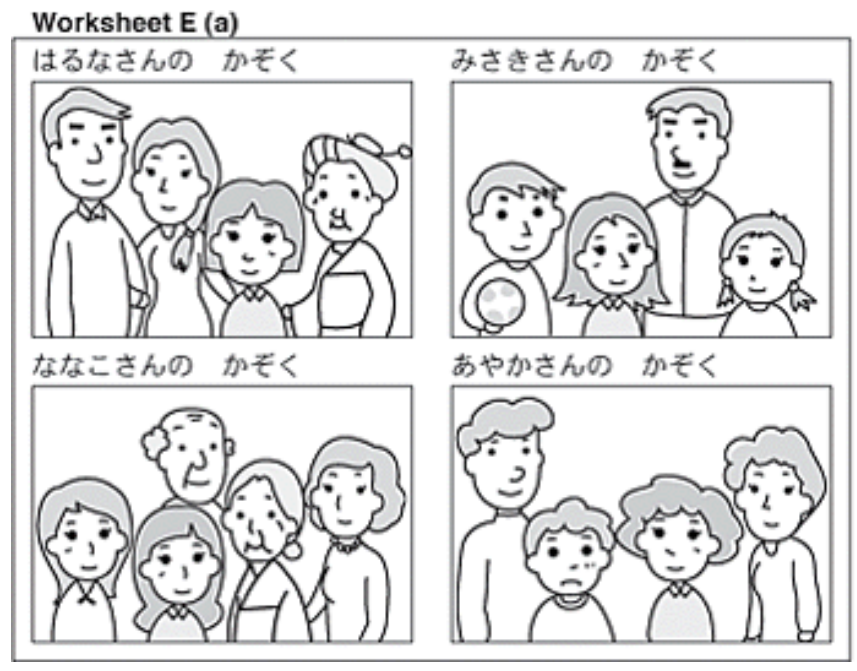

Gambar 3. Worksheet E

Melalui implementasi model-model information gap dalam pembelajaran kaiwa berbasis daring tersebut, kemampuan berbahasa Jepang mahasiswa dapat meningkat karena dalam kegiatan information gap mendekati komunikasi aktual yang tidak hanya menekankan latihan bahasa tetapi juga menggunakan bahasa untuk bertukar makna.

\section{Simpulan dan Saran}

Berdasarkan pembahasan di atas, simpulan yang dapat diperoleh dalam penelitian ini sebagai berikut.

Kemampuan berbahasa Jepang mahasiswa setelah diimplementasikan model-model information gap dalam pembelajaran kaiwa berbasis daring mengalami peningkatan. Hal ini terlihat dari gain hasil pretest dan posttest menunjukkan peningkatan rata-rata nilai sebesar 2.04. Berdasarkan hasil posttest diketahui $86 \%$ mahasiswa yang diimplementasikan modelmodel information gap dalam pembelajaran kaiwa berbasis daring memperoleh nilai di atas 
80 sedangkan sisanya $14 \%$ mahasiswa memperoleh nilai di bawah 80 . Hal ini menunjukkan bahwa kemampuan berbahasa Jepang mahasiswa setelah diimplementasikan model-model information gap adalah baik. Implementasi model-model information gap terbukti mampu meningkatkan kemampuan berbahasa Jepang mahasiswa. Dari hasil angket/kuesioner diperoleh respon positif dari sebagian besar responden terhadap implementasi model-model information gap dalam pembelajaran kaiwa berbasis daring.

Implementasi model-model information gap dalam pembelajaran kaiwa berbasis daring dalam penelitian ini, yaitu information gap antara dua siswa dan information gap antara dua kelompok atau lebih. Berdasarkan hasil penelitian, penulis menyarankan agar materi kaiwa yang diajarkan dengan model-model information gap sebaiknya dipilih dan disesuaikan terlebih dahulu. Implementasi model-model information gap dalam pembelajaran kaiwa berbasis daring membutuhkan waktu yang banyak sehingga disarankan untuk dapat mengatur waktu dengan sebaik-baiknya agar tercapai tujuan pembelajaran yang diharapkan.

\section{Daftar Pustaka}

Aprilina, L. 2018. Efektivitas Metode Information Gap Terhadap Kemampuan Kaiwa Siswa Kelas XI IBB SMA Negeri 1 Bangil Tahun Ajaran 2017/2018. Skripsi tidak diterbitkan. Malang: FIB Universitas Brawijaya.

Arikunto. S. 2010. Prosedur Penelitian: Suatu Pendekatan Praktik. Jakarta: Rineka Cipta.

Kazuhiro, I. 2012. Developing Your Own Activities Information Gap. Diakses dari https://jpf.org.au/classroomresources/jpfmedia/Developing_Your_Own_Activities_Infor mation_Gap.pdf

Sutedi, D. 2009. Penelitian Pendidikan Bahasa Jepang. Bandung: Humaniora.

Tarigan, H.G. 2008. Berbicara sebagai suatu Keterampilan Berbahasa. Bandung: Angkasa. 